\title{
DOSSIÊ POLÍTICA, DIREITO E JUDICIÁRIO: UMA INTRODUÇÃO ${ }^{1}$
}

\author{
Fabrício Ricardo de Limas Tomio Ernani Carvalho
}

"Há alguns anos, a revista New Yorker publicou um cartoon
em que uma mulher jovem, sentada de perna cruzada no sofá,
respondia a um pretendente ajoelhado defronte dela e que
acabava, ao que tudo indicava, de lhe propor casamento. Eis
a sua resposta: 'Interessante. Diga ao seu advogado que
entre em contato com o meu'”
(GALANTER, 1993, p. 103).

Esse é um exemplo que tipifica com humor a profunda transformação que as sociedades ocidentais contemporâneas têm enfrentado, ou seja, "o mundo de nossa experiência direta viu-se invadido, imbuído, colonizado e, de algum modo, diminuído, por uma camada de direito derivativa e inútil" (ibidem).

Essa "invasão" é observada em vários aspectos da vida. O Direito, como parte do aparato regulador da sociedade, ocupa hoje um lugar de destaque. Sobre quase tudo é possível encontrar uma legislação que aborde, ordene ou regule. Destarte, paralelamente a isso tem-se uma participação nunca antes vista do poder Judiciário, como instituição ativa e participante da vida social. Neste dossiê, vamos abordar uma parte destes câmbios, em particular a que se refere à relação entre Política, Direito e Judiciário.

Tocqueville havia chamado atenção, séculos atrás, sobre a participação significativa dos juízes na vida pública da América. A transformação de questões políticas em questões jurídicas era um fenômeno inédito na Europa, mas fazia parte da dinâmica de poder do novo continente. "Duvido [...] que a democracia possa governar muito tempo a sociedade e não poderia crer que hoje em dia uma república possa esperar e conservar a sua existência, se a influência dos juristas nos negócios públicos não crescesse em proporção ao poder do povo". (TOCQUEVILLE, 1977, p. 205)

\footnotetext{
1 A publicação do presente dossiê foi parcialmente patrocinada com recursos do Programa CNJ Acadêmico, com apoio conjunto: da CAPES, do CNJ - Conselho Nacional de Justiça (órgão do Poder Judiciário do Brasil) e dos Grupos de Pesquisa DIRPOLNúcleo de Direito e Política e e-Justiça (Justiça Eletrônica) UFPR, ambos sediados no Programa de Pós-Graduação em Direito da UFPR.
}

Os artigos federalistas (Federalist Papers), escritos por James Madison, Alexander Hamilton e John Jay, explicitam a função de relevo que o poder Judiciário possuía (e possui) na sociedade norte-americana. O papel exercido pelo poder Judiciário é evocado diante da natureza humana. "Mas o que é o próprio governo, senão a maior das críticas à natureza humana? Se os homens fossem anjos, não seria necessário governo algum. Se os homens fossem governados por anjos, o governo não precisaria de controles externos nem internos" (MADISON, HAMILTON \& JAY, 1984, art. 51, p. 350).

Contudo, só a partir de meados século XX o poder Judiciário toma contornos de significância política em escala global. São muitas as explicações para a globalização da importância política do poder Judiciário.

Para Tate e Vallinder (1995), a expansão do poder judicial está ligada à queda do comunismo no Leste europeu e ao fim da União Soviética. O colapso do socialismo real promoveu o liberalismo, o capitalismo e suas instituições de mercado, além de os EUA terem se tornado a única superpotência do planeta. A incorporação do desenho institucional norte-americano ficou em evidência, principalmente após o fim da II Guerra Mundial. "Since World War II, there has been a profound shift in power away from legislatures and toward courts and other legal institutions around the world. This shift, which has been called 'judicialization', has become more or less global in its reach, as evidenced by the fact that it is as marked in Europe, and especially recently in Eastern Europe, as it is in the United States" (FEREJOHN, 2002, p. 41)2.

\footnotetext{
2 "Desde a II Guerra Mundial, tem havido uma profunda guinada de poder, das legislaturas em direção às cortes e outras instituições legais ao redor do mundo. Essa mudança, que foi chama-
} 
Não só Europa Ocidental e os Estados Unidos, mas quase todas as democracias liberais possuem, em boa medida, elementos e características desse processo de expansão do Poder Judiciário, especialmente na arena política (HIRSCH, 2004).

A literatura corrente na área de Ciência Política avançou muito no que tange os estudos dos tribunais constitucionais e sua atuação no âmbito do processo decisório. Diversos trabalhos demonstram o aumento considerável da participação do poder Judiciário na vida pública (SHAPIRO, 1981; TATE \& VALLINDER, 1995; CLAYTON \& GILLMAN, 1999; SWEET, 2000; WORLD BANK, 2003; SADEK, 2004; TAYLOR, 2008; CARVALHO, 2009). No geral, a teoria contramajoritária, defendida nos artigos federalistas, ilumina o campo de estudo. Nessa perspectiva, os tribunais passam a ser analisados como um efetivo poder de veto às ações legislativas dos poderes representativos: poder Executivo e poder Legislativo. "Podemos distinguir al menos tres maneras en las que los tribunales han tomados nuevos e importantes papeles en relación con las legislaturas. Primero, los tribunales se han vistos cada vez más aptos y con mayores deseos de limitar y regular el ejercicio de la autoridad parlamentaria imponiendo límites importantes al poder de las instituciones legislativas. Segundo, cada vez más, los tribunales se han convertido en el lugar donde se hacen las políticas significativas. Y, tercero, los jueces se han vistos más dispuestos a regular la conducción de la actividad política misma construyendo y haciendo valer normas de comportamiento aceptable, tanto para grupos de interés y partidos políticos como para funcionarios electos e designados" (FEREJOHN, 2002, p. 14).

O caráter global da expansão do direito e de suas instituições sobre a política tem atraído um número significativo de estudiosos que passaram a debruçarse sobre o tema e aprofundar o conhecimento acerca das causas e das conseqüências desse fenômeno.

Entre as descobertas podemos destacar duas que estão intrinsicamente ligadas ao desenho institucional: (i) a existência de prerrogativas institucionais que garantam a independência de atuação do poder Judiciário, combinada com a possibilidade de revisão judicial são fatores institucionais que potencializam o processo de judicialização da política (CLAYTON \& GILLMAN, 1999; RÍOS-FIGUERO \& TAYLOR, 2006); (ii) quanto maior for o grau de fragmentação

da de 'judicialização', tornou-se mais ou menos global em seu alcance, como evidenciado pelo fato de encontrar-se tanto na Europa, e recente e especialmente no Leste Europeu, como nos Estados Unidos" (NR). política de uma sociedade, maior serão os níveis de judicialização do conflito politico (FEREJOHN, 2002). $\mathrm{O}$ caso brasileiro reúne as duas situações acima, ou seja, seu sistema político é bastante fragmentado e o poder Judiciário possuir uma ampla gama de prerrogativas (TAYLOR, 2008). Portanto, possui um desenho institucional que incentiva a judicialização da política.

A literatura nacional tem avançado no sentido de compreender a dinâmica desse processo de judicialização da política. Os debates em torno das instituições judiciais e sua relação com o poder, a profissionalização das carreiras jurídicas, a análise dos processos políticos-jurídicos, o Direito e a Economia Política, para destacar alguns temas que os pesquisadores brasileiros tem desenvolvido ${ }^{3}$.

As associações internacionais e nacionais promovem e estimulam o debate ao concederam espaço privilegiado ao tema. A grande reputação dessas associações, como: The American Political Science Association (APSA), International Political Science Association (IPSA), The European Consortium for Political Research (ECPR), Latin American Association of Political Science (LASA), La Asociación Latinoamericana de Ciencia Política (Alacip), Associação Brasileira de Ciência Política (ABCP), Associação Nacional de Pós-graduação em Ciências Sociais (Anpocs), entre tantas outras, reforçam a importância do tema e sua projeção em termos de significância internacional.

Nesse sentido, a iniciativa deste dossiê "Política, Direito e Judiciário" é seguir contribuindo para a consolidação dessa área de investigação, divulgar a produção recente sobre a temática e estimular novos estudos teóricos, empíricos e comparados que aprofundem o conhecimento (causas e efeitos): (i) do processo decisório interno do judiciário, seu funcionamento (policymaking), suas decisões (policy outcomes) e a eficiência ou eficácia da prestação jurisdicional entendida como política pública; (ii) da participação crescente das instituições judiciárias (judicialização) na política, vetando, alterando e, eventualmente, substituindo as decisões dos atores políticos e institucionais vinculados aos poderes Executivo e Legislativo; (iii) do comportamento dos atores jurídicos, crenças de autoridades judiciais e as bases do ativismo do poder Judiciário.

\footnotetext{
3 A produção nacional nessa área tem se institucionalizado gradativamente. O papel de apoio das principais associações nacionais da Ciência Política (ABCP e Anpocs) tem sido fundamental para o desenvolvimento da área, principalmente na manutenção ordinária de Grupos de Trabalhos.
} 
Os três primeiros artigos deste dossiê abordam a criação de uma instituição de autogoverno do poder Judiciário, introduzida no arranjo institucional brasileiro pela "reforma do judiciário" (Emenda Constitucional n. 45/2004): o Conselho Nacional de Justiça (CNJ). A dinâmica das instituições (neste caso, o processo legislativo constituinte que criou o $\mathrm{CNJ}$ ), os interesses dos atores e elites políticas envolvidos na reforma constitucional e os efeitos produzidos pela mudança institucional (regras do jogo) são objeto privilegiado e recorrente da Ciência Política e de campos de estudo correlacionados (como o próprio Direito).

Descrevendo simplificadamente (e conjuntamente), poderíamos propor o seguinte enredo à problemática analisada pelos três artigos sobre o CNJ (mudança institucional, suas causas e os seus efeitos): ( $i$ ) a assembléia constituinte, em 1988, seguindo o legado institucional brasileiro (path dependence), buscando mais garantias ao novo regime e/ou respondendo positivamente às pressões dos grupos organizados do poder Judiciário e profissões afins, manteve e exacerbou as extensas prerrogativas de independência do poder Judiciário com restritos e ineficazes mecanismos de accountability (prestação de contas e responsabilização); (ii) expectativas por maior eficácia ou eficiência da jurisdicionalidade e responsabilização de desvios permitiram que uma maioria qualificada (congressual e de coalizão, porém sensivelmente responsiva aos interesses das elites judiciais, sobretudo do Supremo Tribunal Federal) reformasse a constituição criando um mecanismo de controle interno (CNJ) dos membros do poder Judiciário, mas sem restringir ou alterar significativamente a independência institucional; (iii) o conflito entre prerrogativas constitucionais (autonomia e independência) do poder Judiciário e a inovação constitucional (CNJ) produz efeitos (variáveis e dependentes da dinâmica decisória) sobre a eficácia ou eficiência da prestação de jurisdicionalidade, a responsividade (responsiveness) ou o interesse em ser accountable dos membros do poder Judiciário.

O primeiro desses três artigos que abre o dossiê (“O poder dos juízes”), de Ernani Carvalho e Natália Leitão, aborda as causas do desenho institucional do conselho, argumentando que a criação do Conselho Nacional de Justiça (CNJ) resultou de um arranjo político construído durante o longo processo de reforma constitucional do poder Judiciário. Nesse arranjo, o interesse prevalecente foi o do Supremo Tribunal Federal (STF), resultando na ausência de controle externo do poder Judiciário e em um conselho de justiça dirigido por integrantes da corte constitucional. $\mathrm{O}$ argumento reforça o papel e a presença política dos membros do STF no processo legislativo da EC n. 45/2004, agindo como atores estratégicos na definição do desenho institucional do CNJ. Como decorrência disso, os autores enfatizam em suas conclusões que: os membros do STF são importantes atores políticos, fato reforçado pelas prerrogativas institucionais que garantem a grande independência da suprema corte brasileira; sistemas políticos com alto grau de fragmentação aumentam a probabilidade de os membros do STF influírem nos resultados do processo político; a existência do mecanismo de revisão judicial amplia o grau de influência de supremas cortes, como o STF; a ocorrência de mecanismos informais de persuasão política maximiza o êxito dos juízes do STF para que seus interesses estejam presentes nos polices outcomes do processo legislativo.

O artigo seguinte ("Accountability e independência judicial"), de Fabricio Tomio e Ilton Robl Filho, aborda um problema teórico e prático do Estado democrático: o controle e a autonomia em instituições judiciárias no desenho institucional do CNJ. O artigo trata, primeiramente, da conceituação de accountability judicial. A argumentação não se esgota em uma tipologia, mas na tensão entre accountability e independência no poder Judiciário. Nesse sentido, o problema central abordado poderia ser descrito dessa forma: como resolver a relação institucional (constitucional e teórica) entre independência e accountability das atividades e dos membros do poder Judiciário? O debate teórico inconcluso e o exame do direito-política comparados demonstram que há várias fórmulas teóricas e constitucionais possíveis e que geram, obviamente, resultados distintos. E, nesse sentido, acrescenta-se outra questão: qual a proporção entre independência e accountability e quais as conseqüências (essencialmente esperadas ou incidentalmente produzidas) dessas escolhas de desenho institucional no CNJ? Para responder a essas questões, os autores demonstram que a Constituição de 1988 atribuiu uma substancial independência ao poder Judiciário (garantias institucionais e funcionais) e profundo déficit de accountability judicial. Além disso, analisam o arranjo institucional posterior à EC n. 45/2004 e como as competências do CNJ ampliaram os mecanismos de accountabilities e controle do poder Judiciário, sobretudo dos juízes de primeiro grau e tribunais, mesmo sem controle externo e garantindo à independência judicial decisional.

O terceiro artigo ("Interfaces entre a E-Justiça e a Q-Justiça"), de Cesar Serbena, aborda um efeito da reforma do poder Judiciário e da criação do $\mathrm{CNJ}$ : o impacto do processo digital e eletrônico (E-Justiça) na prestação jurisdicional, como política pública resultante das diretrizes dos tribunais superiores (STF e STJ) e 
induzida pelas políticas implementadas pelo CNJ em busca de eficiência do poder Judiciário. Além de descrever o processo de implantação da política pública da justiça eletrônica (E-Justiça), são analisados os sistemas de avaliação do desempenho do poder Judiciário por meio de análise estatística, coleta de dados e construção de índices de performance do desempenho de juízes e tribunais (justiça quantitativa, ou Q-Justiça). No artigo, são investigadas as interfaces entre E-Justiça e Q-Justiça, os mecanismos de publicização dos dados estatísticos dos outcomes do processo judicial e as expectativas quanto ao aprofundamento da informatização na execução das políticas públicas judiciais (mineração de dados e computação em nuvem). Nesse sentido, o artigo apresenta uma reflexão que transita entre dois mundos aparentemente distantes, mais extremamente próximos (processo jurídico e política pública), para gerar uma terceira problemática, costumeiramente negligenciada por ambos: o exame da eficiência na gestão e execução de políticas públicas geradas por inovações institucionais.

Os outros três artigos que completam o dossiê abordam temas específicos e relevantes da área de estudo já institucionalizada na Ciência Política brasileira e internacional. O quarto artigo ("Ações judiciais, conteúdos políticos”), de Fabiano Engelmann e Márcio Cunha Filho, aborda o tema que se torna clássico e central para a área (também abordado pelos artigos anteriores): a judicialização da(s) política(s). O argumento sustentase empiricamente em uma amostra de ações julgadas pelo poder Judiciário sul-riograndense que têm por objeto demandas por "políticas sociais", analisando-se as "doutrinas jurídicas" que legitimam o "controle jurisdicional" de políticas públicas. Os autores concluem que as categorias de argumentos mobilizados nas decisões judiciais evidenciam uma tendência de ativismo dos atores do poder Judiciário, sustentadas em concepções de políticas que opõem a "unidade do Estado", a "interpretação da Constituição" e a "efetividade do direito" à dinâmica de execução de políticas das administrações públicas (estadual e municipal). Esse estudo, como outros semelhantes, evidencia um dilema presente na judicialização das políticas públicas, sobretudo na execução das políticas públicas por governos locais: onde está o interesse público, nas decisões judicializadas ou nos resultados do processo decisório presentes nas relações Executivo-Legislativo? E qual a legitimidade de cada processo decisório?

O quinto artigo ("O paradoxo das reformas do Estado de Direito") 4 , de Mariana Mota Prado, aborda a relação

\footnotetext{
4 O artigo é uma tradução do original em Inglês "The Paradox of Rule of Law Reforms: How Early Reforms Can Create Obstacles
}

entre Direito, reforma do poder Judiciário e desenvolvimento. Mais especificamente, situa como numerosas reformas no Estado de Direito em países em desenvolvimento geraram poucos sucessos e muitos fracassos. Utilizando-se da abordagem institucional (path-dependence), a autora aprofunda como reformas anteriores criam obstáculos a reformas futuras. $\mathrm{O}$ principal argumento do artigo é que reformas iniciais podem criar valores, práticas e atitudes que se tornarão, por vezes, impedimentos para futuras reformas, fortalecendo grupos de interesse que irão bloquear futuras reformas. Segundo a conclusão, os formuladores de políticas públicas encontram-se diante de um paradoxo: reformas iniciais ambiciosas podem prejudicar os esforços para promover reformas importantes no futuro, criando uma armadilha no processo de reforma (reforma-armadilha). $\mathrm{O}$ caso da reforma do poder Judiciário no Brasil ilustra, no artigo, esse paradoxo e possibilita discutir possíveis estratégias para superar esse impasse.

$\mathrm{O}$ artigo que encerra o dossiê ("Quem ganhou as eleições? A validação dos resultados eleitorais antes da criação da justiça eleitoral"), de Paolo Ricci e Jaqueline Zulini, remete a dificuldade que a geração de cientistas políticos atuais tem em tratar com a origem das instituições políticas. É comum naturalizar arranjos institucionais como se fossem inexoráveis e como se inexistisse qualquer mundo anterior à sua existência. A justiça eleitoral, electoral management body, pouco freqüente em outras democracias, é vista, por juristas e estudiosos da política brasileira, como a única forma de administração e jurisdição do processo eleitoral; embora talvez seja a face mais desconhecida da judicialização da política no Brasil. Para abordar esse mundo, os autores investigam a Primeira República para elucidar a dinâmica político-partidária do contencioso eleitoral em uma fase anterior à consagração da magistratura como órgão proclamador da verdade das urnas, prerrogativa instituída somente com o Código de 1932. Os dados apresentados no artigo revelam que, ao contrário da visão disseminada pela literatura, a degola das oposições não era usual, mas restrita aos anos críticos, quando o situacionismo local não conseguia coordenar as disputas regionais pelo poder. Na maioria dos casos, o parlamento, que arbitrava sobre o reconhecimento dos seus diplomados, tendia a ratificar as escolhas adotadas ao nível subnacional. Ou seja, decisões políticas (inovações institucionais), que introduziram o judiciário como árbitro eleitoral independente, não podem ser vistas como resposta funcional à solução do contencioso político

to Future Ones", publicado na University of Toronto Law Journal, volume 60, página 555. Tradução de Patrícia Galvão Ferreira e revisão da tradução pela própria autora. 
que ocorria no parlamento e entre elites políticas locais. A criação da justiça eleitoral deve estar inserida em um projeto de reforma política mais ampla, que incluiria mecanismos que antecedem à validação dos votos e remetem a um período pouco estudado da história das instituições políticas brasileiras. Mais um espaço para o aprofundamento do legado político-jurídico (pathdependence) das decisões que construíram a institucionalidade atual do estado no Brasil.

Para finalizar, os artigos presentes neste dossiê "Política, Direito e Judiciário" não pretendem esgotar a temática. As áreas das associações, nacionais e internacionais, de Ciência Política, Direito e áreas afins, são pródigas em estudos que fornecem novas questões ao estudo da relação política-direito-instituições. Possivelmente, a pretensão maior do dossiê é incentivar que novos estudos, teórica e/ou empiricamente sustentados, aprofundem a relação entre as instituições (jurídico-políticas) e os resultados (jurídico-políticos) dos processos decisórios em que diferentes atores e autoridades envolvem-se, independentemente do ramo de poder em que estejam inseridos. Certamente, a Revista de Sociologia e Política é um veículo científico que permite, aos artigos aqui apresentados, fomentar esse objetivo ao campo de estudos sobre a política nas instituições jurídicas.

Fabrício Ricardo de Limas Tomio (fabricio.tomio@pq.cnpq.br) é Doutor em Ciência Política pela Universidade Estadual de Campinas (Unicamp) e Professor da Faculdade de Direito da Universidade Federal do Paraná (UFPR).

Ernani Carvalho é (ernani.carvalho@pq.cnpq.br) Doutor em Ciência Política pela Universidade de São Paulo (USP) e Professor do Departamento de Ciência Política da Universidade Federal de Pernambuco (UFPE).

\section{REFERÊNCIAS BIBLIOGRÁFICAS}

CARVALHO, E. 2009. Judicialização da política no Brasil: controle de constitucionalidade e racionalidade política. Análise Social, Lisboa, v. XLIV, n. 191, p. 315-335, abr.

CLAYTON, C. W. \& GILLMAN, H. (eds.). 1999. Supreme Court Decision-Making: New institutionalist approaches. Chicago: University of Chicago.

FEREJOHN, J. 2002. Judicializing Politics Politicizing Law. Law and Contemporary Problems, Durham, v. 65, n. 3, p. 41-68, Summer. Disponível em: http:// scholarship.law.duke.edu/cgi/viewcontent.cgi? article $=1258 \&$ context $=$ lcp. Acesso em: $30 . a b r .2013$.

GALANTER, M. 1993. Direito em abundância: a atividade legislativa no Atlântico Norte. Revista Crítica de Ciências Sociais, Coimbra, n. 36, p. 103-145, fev.

HIRSCH, R. 2004. Toward Juristocracy. Cambridge (MA): Harvard University.

MADISON, A.; HAMILTON, J. \& JAY, J. 1984. Os federalistas. Brasília: UNB.

POZAS-LOYO, A. \& RIOS-FIGUEROA, J. 2011. The Politics of Amendment Processes: Supreme Court Influence in the Design of Judicial Councils. Texas Law Review, Austin, v. 89, p. 1807-1834. Disponível em: http://www.texaslrev.com/wpcontent/uploads/Pozas-Loyo-Rios-Figueroa-89-
TLR-1807.pdf. Acesso em: 30.abr.2013.

RÍOS-FIGUEROA, J. \& TAYLOR, M. M. 2006. Institutional Determinants of the Judicialisation of Policy in Brazil and México. Journal of Latin American Studies, Cambridge (UK), v. 38, n. 4, p. 739-766, Nov.

SADEK, M. T. 2004. Judiciário: mudanças e reformas. Estudos Avançados, São Paulo, v. 18, n. 51, p. 79-101, maio-ago. Disponível em: http:// www.scielo.br/pdf/ea/v18n51/a05v1851.pdf. Acesso em: 30.abr.2013.

SHAPIRO, M. 1986. Courts: A comparative and political analysis. Chicago: The University of Chicago.

SWEET, A. S. 2000. Governing with Judgers: Constitutional Politics in Europe. Oxford: Oxford University.

TATE, T. \& VALLINDER, C. N. 1995. The Global Expansion of Judicial Power: The judicialization of politics. New York: New York University.

TAYLOR, M. 2008. Judging Policy: Courts and Policy Reform in Democratic Brazil. Stanford: Stanford University.

TOCQUEVILLE, A. 1977. A democracia na América. São Paulo: USP.

WORLD BANK. 2003. Legal and Judicial Reform: Strategic directions. Washington (DC): World Bank. 